Article

\title{
Synthesis and Characterization of Process-Related Impurities of Antidiabetic Drug Linagliptin
}

\author{
Yiwen Huang, Xiaoqing He, Taizhi Wu * and Fuli Zhang * \\ Shanghai Institute of Pharmaceutical Industry, China State Institute of Pharmaceutical Industry, \\ 285 Gebaini Road, Pudong, Shanghai 201203, China; cpuhyw2010@163.com (Y.H.); xuesitu@163.com (X.H.) \\ * Correspondence: wu.taizhi@sipi.com.cn (T.W.); zhangfuli1@sinopharm.com (F.Z.); \\ Tel.: +86-21-2057-2000 (ext. 5036) (T.W.); +86-21-2057-2000 (ext. 5069) (F.Z.)
}

Academic Editor: Diego Muñoz-Torrero

Received: 22 June 2016; Accepted: 5 August 2016; Published: 9 August 2016

\begin{abstract}
Linagliptin, a xanthine derivative, is a highly potent, selective, long-acting and orally bioavailable DPP-4 inhibitor for the treatment of type 2 diabetes. During the process development of linagliptin, five new process-related impurities were detected by high performance liquid chromatography (HPLC). All these impurities were identified, synthesized, and subsequently characterized by their respective spectral data (MS, HRMS, ${ }^{1} \mathrm{H}-\mathrm{NMR},{ }^{13} \mathrm{C}-\mathrm{NMR}$ and IR) as described in this article. The identification of these impurities should be useful for quality control and the validation of the analytical method in the manufacture of linagliptin.
\end{abstract}

Keywords: linagliptin; type 2 diabetes; impurities; synthesis; characterization

\section{Introduction}

The presence of impurities in a drug substance can have a significant impact on the quality and safety of the drug product [1]. According to the general guidelines on impurities in drug substances recommended by the International Conference on Harmonization (ICH), any impurities present in the drug substance greater than a level of $0.10 \%$ for drugs with a maximum daily dose equal to or lesser than $2 \mathrm{~g}$ should be identified and characterized [2]. On one hand, the identification and characterization of process-related impurities can guide us in controlling these impurities within the acceptable level by improving reaction conditions in turn. On the other hand, impurities in pure form are also needed to validate the analytical method including checking the system suitability and relative correction factor.

Linagliptin (1, Figure 1), a highly potent, selective, long-acting and orally bioavailable DPP-4 inhibitor for the treatment of type 2 diabetes, is chemically known as (R)-8-(3-aminopiperidin-1-yl)-7(but-2-yn-1-yl)-3-methyl-1-((4-methylquinazolin-2-yl)methyl)-1H-purine-2,6(3H,7H)-dione [3].

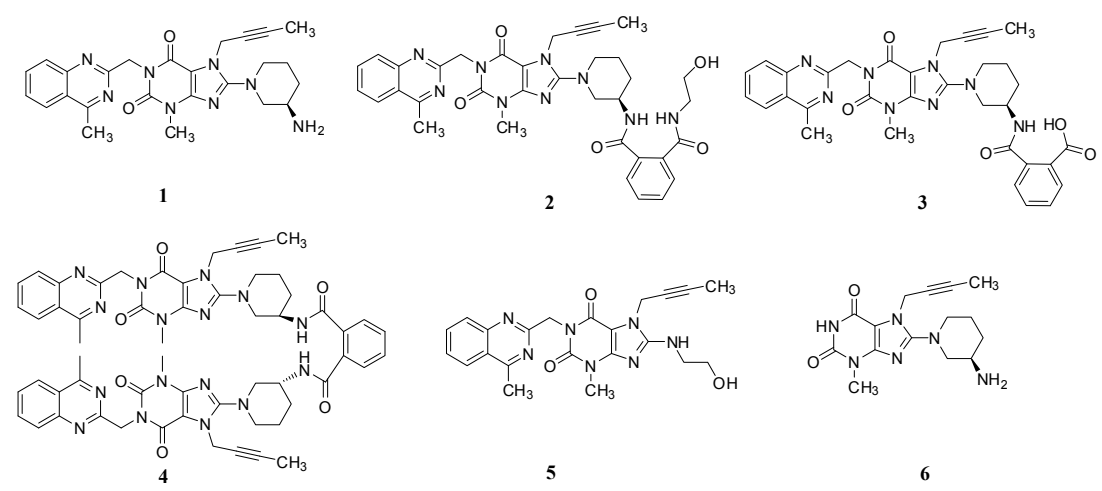

Figure 1. Chemical structures of linagliptin and process-related impurities. 
In the industrial manufacturing process (Scheme 1) of linagliptin by the Boehringer Ingelheim company [4], cyclization of 1-(2-aminophenyl)ethanone (7) with 2-chloroacetonitrile (8) in the presence of hydrogen chloride afforded 2-(chloromethyl)-4-methylqu inazoline (9, yield $74 \%-85 \%)$ which condensed with 8-bromo-7-(but-2-yn-1-yl)-3-methyl-1H-purine-2,6(3H,7H)-dione (10) in the presence of sodium carbonate as a basic reagent, giving 8-bromo-7-(but-2-yn-1-yl)-3-methyl-1-((4-methylquinazolin -2-yl)methyl)- $1 H$-puri ne-2,6(3H,7H)-dione (11, yield 76\%-83\%). Subsequently, the condensation of 11 with (R)-2-(piperidin-3-yl)isoindoline-1,3-dione D-(-)-tartaric acid (12) using diisopropylethylamine as a basic reagent provided ( $R$ )-7-(but-2-yn-1-yl)-8-(3-(1,3-dioxoisoindolin-2-yl) pipe ridin-1-yl)-3-methyl1-((4-methylquinazolin-2-yl)methyl)-1H-purine-2,6(3H,7H)-dione (13, yield 90\%-94\%). Compound 13 finally converted to the desired linagliptin (1) in $81.9 \%$ yield via aminolysis using ethanolamine as the aminolysis agent.

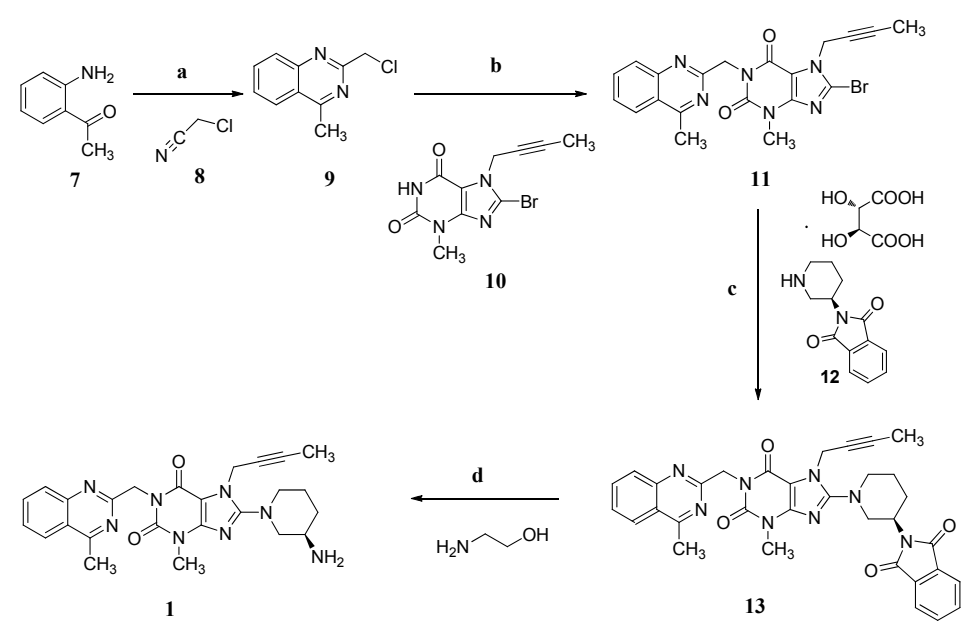

Scheme 1. Synthesis of linagliptin (1). Conditions: (a) $\mathrm{HCl}, 1,4$-dioxane, $6{ }^{\circ} \mathrm{C}, 2 \mathrm{~h}, 74 \%-85 \%$; (b) $\mathrm{Na}_{2} \mathrm{CO}_{3}$, $\mathrm{N}$-methyl-2-pyrrolidone (NMP), $140{ }^{\circ} \mathrm{C}, 2 \mathrm{~h}, 76 \%-83 \%$; (c) diisopropanolamine, NMP, $140{ }^{\circ} \mathrm{C}, 2 \mathrm{~h}$, $90 \%-94 \%$; (d) ethanolamine, $\mathrm{THF} / \mathrm{H}_{2} \mathrm{O}, 60{ }^{\circ} \mathrm{C}, 3 \mathrm{~h}, 81.9 \%$.

However, the literature search did not reveal much work on the impurity research of linagliptin. The impurity profile of linagliptin in this synthetic route is different from the earlier reported study $[5,6]$, which makes it more challenging to identify the unknown impurities formed in small quantities in the drug substance. Since most of the time it is very difficult to identify and control impurities within acceptable levels in the process, some advanced purification techniques for an active drug substance may then be taken into account, such as the continuous-flow process [7], organic solvent nanofiltration (OSN) [8], molecularly imprinted membranes for OSN [9] and counter current chromatography (CCC), as a valuable addition to the chromatography toolbox [10].

Hence, a comprehensive study was undertaken to identify and synthesize the impurities in a sample of linagliptin as described in this article. The study will help to understand the formation of the impurities in linagliptin synthesis and provide a clue on how to obtain a pure drug substance.

\section{Results and Discussion}

\subsection{Structures of Impurities}

During the process development of linagliptin, five new process-related impurities were detected by high performance liquid chromatography (HPLC) (Figure 2), varying from $0.15 \%$ to $0.5 \%$, and the molecular weight of the respective impurities was identified through liquid chromatographic mass spectrometry (LC-MS). From the molecular weight information, an extensive study was undertaken to predict and synthesize the five new impurities. Finally, all these impurities were synthesized and subsequently subjected to spectral analysis. The five predicted and synthesized impurities showed the 
same retention time with those detected in HPLC. Based on the spectral data, these impurities were characterized as the structures shown in Figure 1. The five new impurities are all reported here for the first time.

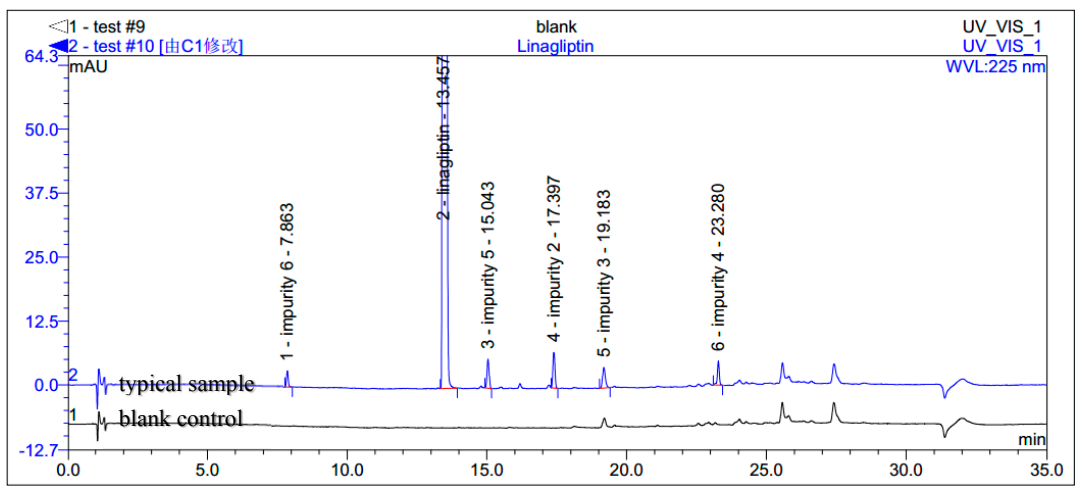

Figure 2. Typical HPLC chromatogram of linagliptin with impurities.

\subsection{Source of Impurities}

The synthesis of linagliptin involved the aminolysis of $\mathbf{1 3}$ using 10 equivalents of ethanolamine [4]. Compound $\mathbf{2}$ is the by-product in this step, formed from incomplete aminolysis. Impurity 2 was further hydrolyzed to afford impurity 3 due to water/tetrahydrofuran (THF) as a solvent. The formed linagliptin moiety (1) reacted with starting material 13 or with 2, providing impurity 4 . During the condensation of 11 with 12 to afford 13, the intermediate $\mathbf{1 1}$ cannot be converted completely and may remain in the intermediate 13. Unfortunately, the small amount of $\mathbf{1 1}$ remaining in the intermediate $\mathbf{1 3}$ reacted with ethanolamine in the next aminolysis process, which explains the formation of impurity 5. Similarly, during the condensation of $\mathbf{1 0}$ with $\mathbf{9}$ to afford 11, the intermediate $\mathbf{1 0}$ cannot be converted completely and may remain in the intermediate 11. Subsequently, $\mathbf{1 0}$ remaining in the intermediate $\mathbf{1 1}$ took part in the condensation reaction with $\mathbf{1 2}$ and in the aminolysis reaction in the next two steps, which finally leads to the formation of impurity $\mathbf{6}$ (Scheme 2). As a result, the five impurities accounted for $0.4 \%, 0.32 \%, 0.27 \%, 0.33 \%$ and $0.16 \%$, respectively, in the drug substance.

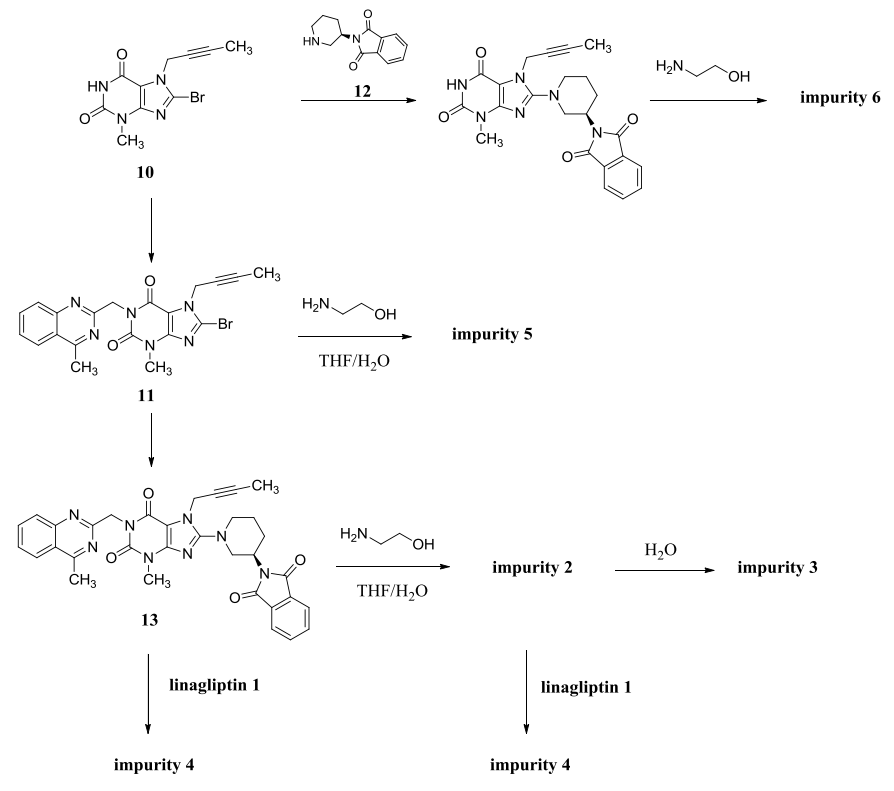

Scheme 2. Source of impurities of linagliptin. 


\subsection{Preparation and Characterization of Impurities}

Compound $\mathbf{2}$ was synthesized by incomplete aminolysis of $\mathbf{1 3}$. In order to prepare $\mathbf{2}$ in good yield, we replaced the solvent of THF/ $\mathrm{H}_{2} \mathrm{O}$ with dichloromethane $\left(\mathrm{CH}_{2} \mathrm{Cl}_{2}\right)$ to obtain a homogeneous system and a smaller inventory ratio of ethanolamine was used for more moderate aminolysis conditions (Scheme 3).

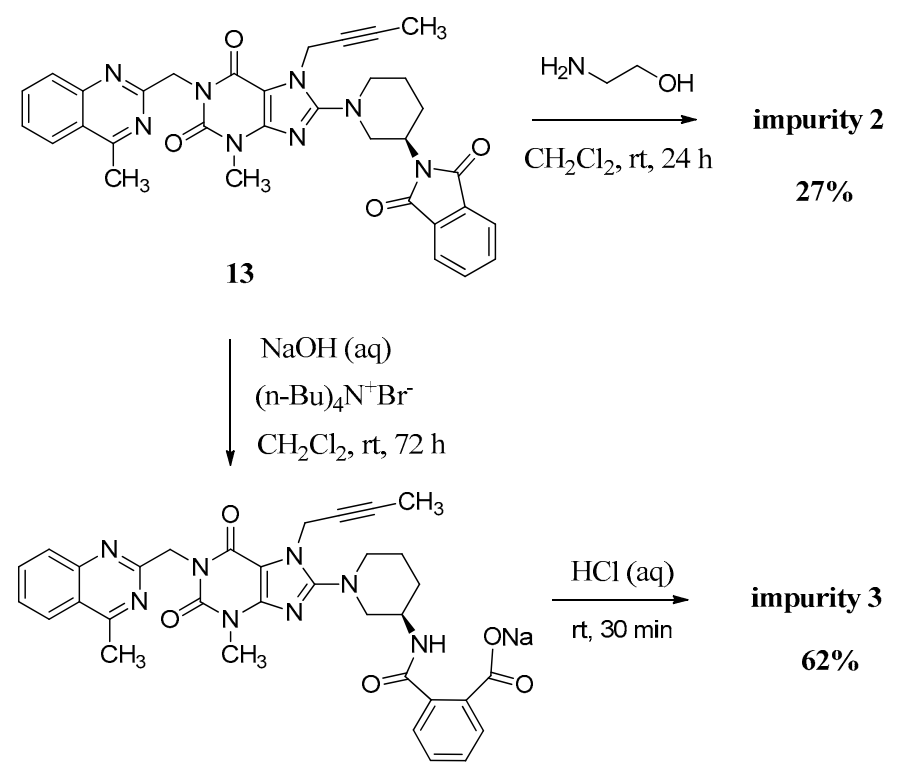

Scheme 3. Preparation of impurity 2 and 3.

The mass spectrum of 2 showed a molecular ion peak at $m / z 686.23(\mathrm{M}+\mathrm{Na})^{+}$in positive ion mode, indicating the mass of this compound to be 663 . The ${ }^{1} \mathrm{H}-\mathrm{NMR}$ of this compound revealed three additional $\mathrm{D}_{2} \mathrm{O}$ exchangeable signals at $8.35,6.95$ and 3.70, indicating the two amide $\mathrm{N}-\mathrm{H}$ protons and one $\mathrm{O}-\mathrm{H}$ proton. Additional signals observed in the region of 8.04-7.47 indicated eight aromatic $\mathrm{C}-\mathrm{H}$ protons. In the IR spectrum, observed bands at 3473 and $3263 \mathrm{~cm}^{-1}$ indicated the amide $\mathrm{N}-\mathrm{H}$ and $\mathrm{O}-\mathrm{H}$ stretching. The ${ }^{13} \mathrm{C}-\mathrm{NMR}$ revealed 35 carbon atoms and further Distortionless Enhancement by Polarization Transfer (DEPT) exhibited eight secondary carbon atoms. Based on all the spectral data (MS, HRMS, ${ }^{1} \mathrm{H}-\mathrm{NMR},{ }^{13} \mathrm{C}-\mathrm{NMR}$ and IR), the structure of impurity 2 was confirmed as $(R)-\mathrm{N}^{1}$-(1-(7-(but2-yn-1-yl)-3-methyl-1-((4-methylquinazolin-2-yl)methyl)-2,6-dioxo-2,3,6,7-tetrahydro-1H-purin-8-yl) piperidin-3-yl)- $N^{2}$-(2-hydroxyethyl)phthalamide.

Compound $\mathbf{3}$ was prepared by the alkali hydrolysis of $\mathbf{1 3}$ with phase transfer catalyst (Scheme 3). The undesired product 1 from excessive hydrolysis can be removed by $\mathrm{CH}_{2} \mathrm{Cl}_{2}$.

The mass spectrum of 3 exhibited a molecular ion peak at $m / z 643.25(\mathrm{M}+\mathrm{Na})^{+}$in positive ion mode and $\mathrm{m} / \mathrm{z} 619.31(\mathrm{M}-\mathrm{H})^{-}$in negative ion mode, indicating the mass of this compound to be 620 . The ${ }^{1} \mathrm{H}-\mathrm{NMR}$ of this impurity revealed two $\mathrm{D}_{2} \mathrm{O}$ exchangeable signals at 12.86 and 8.35 , indicating one acid $\mathrm{O}-\mathrm{H}$ proton and one amide $\mathrm{N}-\mathrm{H}$ proton, and an additional eight proton signals at 7.41-8.25 corresponding to aromatic protons. Interestingly, we found the methyl group $\left(\mathrm{CH}_{3}\right)$ in quinazoline at $\delta 2.89 \mathrm{ppm}$ is acidic at a certain degree, which explains the proton exchange of the $\mathrm{CH}_{3}$ group with $\mathrm{D}_{2} \mathrm{O}$ which takes place sometimes. The proton exchange's resulting compound (3- $d$, Figure 3) also explains the proton splitting of the $\mathrm{CH}_{3}$ group, which showed a triplet peak with one proton of $2.89 \mathrm{ppm}$ in the ${ }^{1} \mathrm{H}-\mathrm{NMR}$ with $\mathrm{D}_{2} \mathrm{O}$ added (Figure 3). The IR spectrum of 3 exhibited a band at $3527 \mathrm{~cm}^{-1}$ corresponding to amide N-H stretching, and $3255 \mathrm{~cm}^{-1}$ for acid O-H stretching. The ${ }^{13} \mathrm{C}-\mathrm{NMR}$ revealed 33 carbon atoms and further DEPT showed six secondary carbon atoms. Impurity 3 was characterized by all respective spectral data (MS, HRMS, ${ }^{1} \mathrm{H}-\mathrm{NMR},{ }^{13} \mathrm{C}-\mathrm{NMR}$ 
and IR) as (R)-2-((1-(7-(but-2-yn-1-yl)-3-methyl-1-((4-methylquinazolin-2-yl)methyl)-2,6-dioxo-2,3,6,7tetrahydro-1H-purin-8-yl)piperidin-3-yl)carbamoyl)benzoic acid.

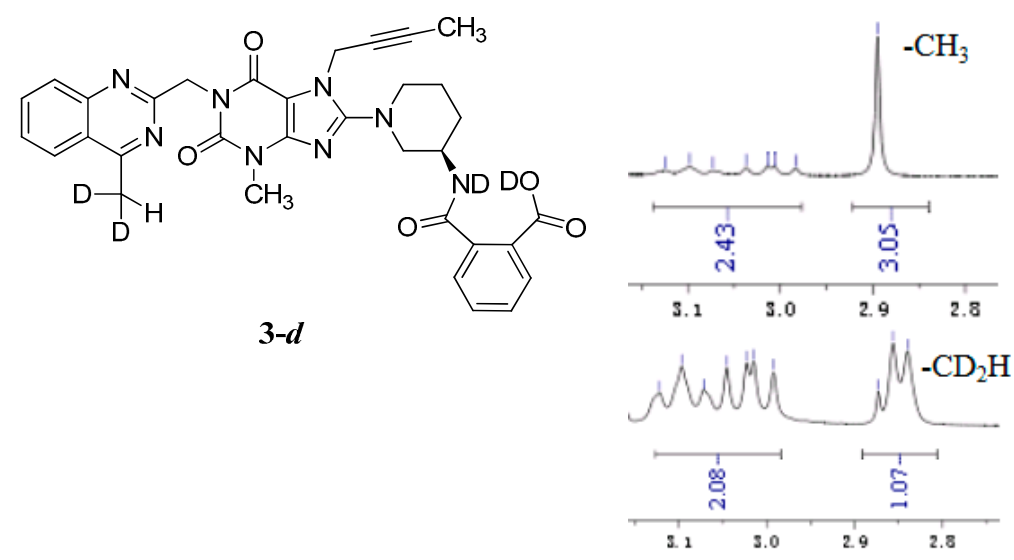

Figure 3. Structures and partial ${ }^{1} \mathrm{H}-\mathrm{NMR}$ spectrum of 3-d.

We can only obtain compound 4 with the low yield of $1.5 \%$ directly via $\mathbf{1 3}$ reacting with the linagliptin moiety (1). Instead, we have exploited a different concept for the synthesis of compound 4 starting from phthaloyl dichloride (14). However, $12 \%$ of the single-benzoyl chloride compound 15 and $11 \%$ of the cyclization product 13 would be generated meanwhile due to the steric hindrance from linagliptin, which influenced the purity of 4 . We reduced them to below $0.3 \%$ and finally got compound 4 with a high purity of $99.15 \%$ by washing the reaction mass with $\mathrm{CH}_{2} \mathrm{Cl}_{2}$ and aqueous sodium hydroxide solution instead of the column chromatography (Scheme 4).

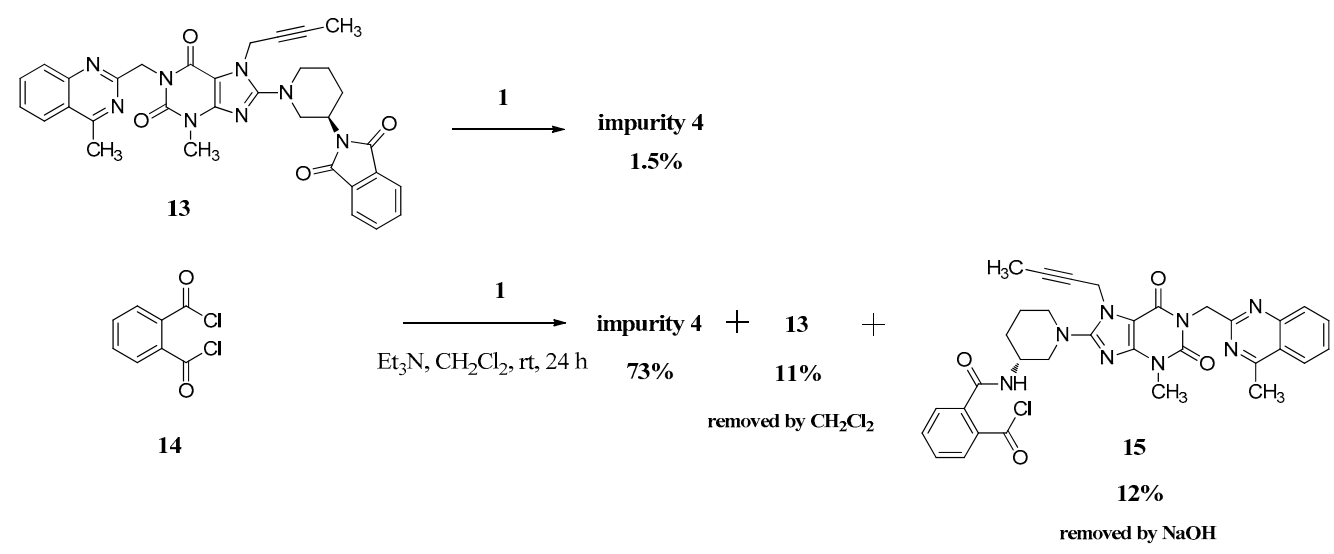

Scheme 4. Preparation of impurity 4.

The mass spectrum of 4 exhibited a molecular ion peak at $m / z 1075.24(\mathrm{M}+\mathrm{H})^{+}, 1097.22(\mathrm{M}+\mathrm{Na})^{+}$ in positive ion mode, indicating the mass of this compound to be 1074. The molecular formula of this compound was $\mathrm{C}_{58} \mathrm{H}_{58} \mathrm{~N}_{16} \mathrm{O}_{6}$ as confirmed by the high resolution mass spectrum (HRMS). In the IR spectrum the observed band at $3243 \mathrm{~cm}^{-1}$ indicated the amide $\mathrm{N}-\mathrm{H}$. The ${ }^{13} \mathrm{C}-\mathrm{NMR}$ showing 29 carbon atoms indicated the symmetry in the structure of compound 4 . Based on all the spectral data (MS, HRMS, ${ }^{1} \mathrm{H}-\mathrm{NMR},{ }^{13} \mathrm{C}-\mathrm{NMR}$ and IR), the structure of impurity 4 was confirmed as $N, N$-bis((R)-1-(7-(but-2-yn-1-yl)-3-methyl-1-((4-methylquinazolin-2-yl)methyl)-2,6-dioxo-2,3,6,7tetrahydro-1H-purin-8-yl)piperidin-3-yl)phthalamide. 
Compound 5 was independently provided via the condensation of compound 11 with ethanolamine. In order to prepare 5 in good yield, we replaced the solvent of tetrahydrofuran/water with toluene to obtain a homogeneous system and a more violent reaction temperature. The increasing inventory ratio of ethanolamine also contributed to the high yield of $94 \%$ (Scheme 5).

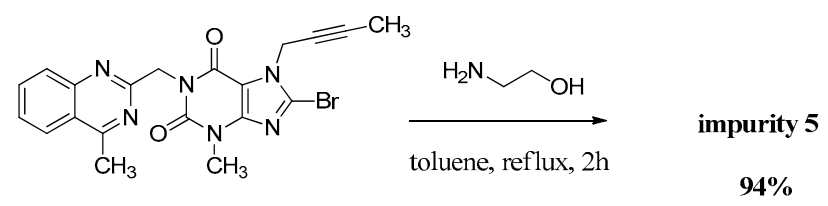

11

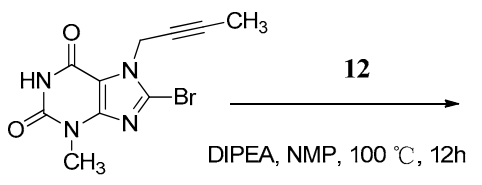

10

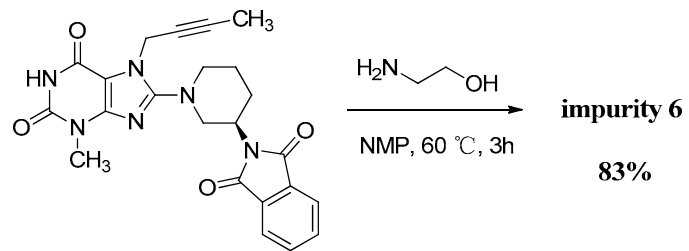

Scheme 5. Preparation of impurities 5 and 6.

The mass spectrum of 5 showed a molecular ion peak at $m / z 456.51(\mathrm{M}+\mathrm{Na})^{+}$in positive ion mode, indicating the mass of this compound to be 433 . The ${ }^{1} \mathrm{H}-\mathrm{NMR}$ of this compound revealed two $\mathrm{D}_{2} \mathrm{O}$ exchangeable signals at 7.23 and 4.78 , indicating the $\mathrm{N}-\mathrm{H}$ and $\mathrm{O}-\mathrm{H}$ protons, and an additional four proton signals at 7.62-8.25 corresponding to aromatic protons. In the IR spectrum the observed bands at 3446 and $3364 \mathrm{~cm}^{-1}$ indicated the $\mathrm{N}-\mathrm{H}$ and $\mathrm{O}-\mathrm{H}$ stretching. The ${ }^{13} \mathrm{C}-\mathrm{NMR}$ revealed 22 carbon atoms and DEPT showed four secondary carbon atoms. Based on all the spectral data (MS, HRMS, ${ }^{1} \mathrm{H}-\mathrm{NMR}$, ${ }^{13} \mathrm{C}-\mathrm{NMR}$ and IR), the structure of impurity 5 was confirmed as 7-(but-2-yn-1-yl)-8-((2-hydroxyethyl) amino)-3-methyl-1-((4-methylquinazolin-2- yl)methyl)- $1 \mathrm{H}$-purine-2,6(3H,7H)-dione.

Compound $\mathbf{6}$ was independently synthesized, starting from compound 10, following a synthetic process analogous to that of linagliptin. Differently, we have exploited a one-pot process for the synthesis of compound 6 instead of the two-step operation in greater yield (Scheme 5).

The mass spectrum of 6 showed a molecular ion peak at $\mathrm{m} / \mathrm{z} 317.14(\mathrm{M}+\mathrm{H})^{+}$in positive ion mode, indicating the mass of this compound to be 316, which is $156 \mathrm{amu}$ less than that of linagliptin (1). The ${ }^{1} \mathrm{H}-\mathrm{NMR}$ of this compound revealed two $\mathrm{D}_{2} \mathrm{O}$ exchangeable signals at 10.94 and 8.27 , indicating the imide $\mathrm{N}-\mathrm{H}$ proton and $\mathrm{N}-\mathrm{H}_{2}$ proton, and no additional aromatic protons were observed. In the IR spectrum the observed band at $3021 \mathrm{~cm}^{-1}$ indicated the imide N-H stretching and double peaks of 3115 and $3074 \mathrm{~cm}^{-1}$, corresponding to primary amine $\mathrm{N}-\mathrm{H}$ stretching. The ${ }^{13} \mathrm{C}$-NMR revealed 15 carbon atoms and DEPT showed five secondary carbon atoms. Impurity 6 was characterized by all respective spectral data (MS, HRMS, ${ }^{1} \mathrm{H}-\mathrm{NMR},{ }^{13} \mathrm{C}-\mathrm{NMR}$ and IR) as (R)-8-(3-aminopiperidin-1-yl)-7-(but-2-yn-1-yl)-3-methyl-1H-purine-2,6(3H,7H)-dione.

\section{Experimental Section}

\section{General Information}

The compound 11 (chemical purity 98.36\%), 13 (chemical purity $97.92 \%$; chiral purity $99.97 \%$ ) and 1 (chemical purity $98.35 \%$; chiral purity $99.97 \%$ ) were prepared according to the literature procedure [4]. Other materials, solvents and reagents were of commercial origin and used without additional operations.

The ${ }^{1} \mathrm{H}$ - and ${ }^{13} \mathrm{C}-\mathrm{NMR}$ spectra were recorded on a Bruker Arance III $400 \mathrm{MHz}$ spectrometer. The solvents used were DMSO- $d_{6}$ or $\mathrm{CDCl}_{3}$. The ${ }^{1} \mathrm{H}-\mathrm{NMR}$ chemical shift values were reported as $\delta \mathrm{ppm}$ 
relative to tetramethylsilane (TMS) and the ${ }^{13} \mathrm{C}-\mathrm{NMR}$ chemical shift values were reported on $\delta \mathrm{ppm}$ relative to DMSO- $d_{6}$ or $\mathrm{CDCl}_{3}$. DEPT spectra revealed the presence of methyl and methine groups as positive peaks and methylene as negative peaks. The IR spectra were recorded in the solid state as $\mathrm{KBr}$ dispersion using a NICOLET 670 FT-IR spectrophotometer. Mass spectra and high resolution mass spectrum were recorded on Agilent 6120B series single quadrupole LC-MS and Q-Tof micro YA019 instrument. Melting points were measured on a WRS-1B apparatus. The specific rotation was calculated from an optical rotation measurement performed on the Autopol IV, serial number 80799 (Rudolph, Hackettstown, NJ, USA) at the wavelength of $589 \mathrm{~nm}$ (D line of a sodium lamp), at $20{ }^{\circ} \mathrm{C}$.

The HPLC analyses were recorded on a Dionex UItiMate 3000 HPLC instrument using Agilent Eclipse XDB C18 column $(150 \mathrm{~mm} \times 4.6 \mathrm{~mm}, 5 \mu \mathrm{m})$ in a thermostated column heater at $55^{\circ} \mathrm{C}$. The mobile phases consisting of $\mathrm{A}(0.1 \%$ methanoic acid, $\mathrm{pH} 2.5)$ and $\mathrm{B}$ (acetonitrile) were used with the gradient mode at the flow rate of $1.5 \mathrm{~mL} / \mathrm{min}$. The UV detection at $225 \mathrm{~nm}$ was used. Initial gradient starts with $5 \%$ of $\mathrm{B}$ and at $18 \mathrm{~min}$ it was set to $40 \%$. The ratio had been set to $70 \%$ at $30 \mathrm{~min}$ and at $30.1 \mathrm{~min}$ it was $5 \%$, which continued up to $35 \mathrm{~min}$. The samples were diluted in acetonitrile with a concentration of $0.5 \mathrm{mg} / \mathrm{mL}$. The injection volume was $5 \mu \mathrm{L}$. Limit of Detection (LOD) was $0.10 \mu \mathrm{g} / \mathrm{mL}$ or $0.02 \%$ for impurities $\mathbf{2 , 3}, \mathbf{4}, \mathbf{5}$ and $0.15 \mu \mathrm{g} / \mathrm{mL}$ or $0.03 \%$ for impurity 6. Limit of Quantity (LOQ) was $0.25 \mu \mathrm{g} / \mathrm{mL}$ or $0.05 \%$ for impurities $2,3,4,5$ and $0.33 \mu \mathrm{g} / \mathrm{mL}$ or $0.07 \%$ for impurity 6 .

This HPLC method further subjected for LC-MS. Samples were run in Electro-Spray Ionization positive mode (ESI+) and $12 \mathrm{~L} / \mathrm{min}$ nebulizer gas flow rate. The fragmentor voltage was $70 \mathrm{~V}$ and capillary voltage was maintained at $3.0 \mathrm{kV}$. The drying gas temperature was at $350{ }^{\circ} \mathrm{C}$.

The detailed spectral data (IR, ${ }^{1} \mathrm{H}-\mathrm{NMR},{ }^{13} \mathrm{C}-\mathrm{NMR}$, MS, HRMS) of the compounds $\mathbf{2 - 6}$ as well as the HPLC chromatogram of the compounds 1-6 are provided in the Supplementary Materials.

(R)-N $N^{1}-(1-(7-(B u t-2-y n-1-y l)-3-m e t h y l-1-((4-m e t h y l q u i n a z o l i n-2-y l) m e t h y l)-2,6-i o x o-2,3,6,7-t e t r a h y d r o-1 H-$ purin-8-yl)piperidin-3-yl)- $N^{2}-(2-h y d r o x y e t h y l)$ phthalamide (2). To a stirred solution of compound $\mathbf{1 3}$ (5.0 g, $0.008 \mathrm{~mol})$ in $\mathrm{CH}_{2} \mathrm{Cl}_{2}(50.0 \mathrm{~mL})$ was added ethanolamine $(1.5 \mathrm{~g}, 0.024 \mathrm{~mol})$ and maintained the reaction mass at room temperature for $24 \mathrm{~h}$. Then added $15 \mathrm{~mL} \mathrm{H}_{2} \mathrm{O}$ stirring for $30 \mathrm{~min}$ to dilute ethanolamine. The isolated solid was collected by filtration and washed with $10 \mathrm{~mL} \mathrm{H}_{2} \mathrm{O}$ and $20 \mathrm{~mL} \mathrm{CH}_{2} \mathrm{Cl}_{2}$. Then dried to yield 2 as a light yellow solid (1.5 g, 27.3\%), HPLC purity $97.52 \%$; m.p. $189-192{ }^{\circ} \mathrm{C} ;[\alpha]_{\mathrm{D}}^{20}$ -32.567 ( $c=1 \mathrm{~g} / 100 \mathrm{~mL}$, DMSO); IR (KBr) $v_{\max }$ 3473, 3263 (amide $\mathrm{N}-\mathrm{H}_{v}, \mathrm{O}-\mathrm{H}_{v}$ ); 3062 (aromatic $\left.\mathrm{C}-\mathrm{H}_{v}\right) ; 2937,2850\left(\mathrm{C}-\mathrm{H}_{v}\right) ; 2230\left(\mathrm{C} \equiv \mathrm{C}_{v}\right) ; 1698,1662\left(\mathrm{C}=\mathrm{O}_{v}\right) ; 1522\left(\right.$ aromatic $\mathrm{C}=\mathrm{C}_{v}$, aromatic $\left.\mathrm{C}=\mathrm{N}_{v}\right)$; 1440, $1400\left(\mathrm{C}-\mathrm{H}_{\delta}\right) ; 1228\left(\mathrm{C}-\mathrm{O}_{\gamma}\right) ; 763\left(\right.$ aromatic $\left.\mathrm{C}-\mathrm{H}_{\gamma}\right) \mathrm{cm}^{-1} ;{ }^{1} \mathrm{H}-\mathrm{NMR}\left(400 \mathrm{MHz}, \mathrm{CDCl}_{3}\right) \delta 8.35(\mathrm{~d}$, $J=6.6 \mathrm{~Hz}, 1 \mathrm{H}), 8.04(\mathrm{~d}, J=8.2 \mathrm{~Hz}, 1 \mathrm{H}), 7.89(\mathrm{~d}, J=8.4 \mathrm{~Hz}, 1 \mathrm{H}), 7.82-7.76(\mathrm{~m}, 1 \mathrm{H}), 7.64-7.52(\mathrm{~m}, 3 \mathrm{H})$, $7.47(\mathrm{~m}, 2 \mathrm{H}), 6.95(\mathrm{t}, J=5.6 \mathrm{~Hz}, 1 \mathrm{H}), 5.56(\mathrm{~s}, 2 \mathrm{H}), 4.89(\mathrm{q}, J=2.0 \mathrm{~Hz}, 2 \mathrm{H}), 4.31(\mathrm{~s}, 1 \mathrm{H}), 3.78(\mathrm{~m}, 2 \mathrm{H}), 3.70$ $(\mathrm{m}, 2 \mathrm{H}), 3.60(\mathrm{~m}, 2 \mathrm{H}), 3.52(\mathrm{~m}, 2 \mathrm{H}), 3.40(\mathrm{~m}, 1 \mathrm{H}), 3.23(\mathrm{~s}, 3 \mathrm{H}), 2.91(\mathrm{~s}, 3 \mathrm{H}), 2.17-2.10(\mathrm{~m}, 1 \mathrm{H}), 1.92(\mathrm{~m}$, 2H), 1.75 (not resolved, $4 \mathrm{H}) ;{ }^{13} \mathrm{C}-\mathrm{NMR}\left(100 \mathrm{MHz}\right.$, DMSO- $\left.d_{6}\right) \delta 169.29,168.75,168.46,161.44,156.37$, 153.80, 151.41, 149.51, 148.03, 136.58, 136.51, 134.51, 129.80, 129.67, 128.33, 128.26, 128.02, 127.57, 126.13, $122.94,103.90,81.74,74.21,60.22,53.84,50.47,46.13,46.08,42.55,35.90,29.90,29.59,23.53,22.01,3.55$; HRMS (ESI) $m / z 664.3019$ (calcd for $\mathrm{C}_{35} \mathrm{H}_{38} \mathrm{~N}_{9} \mathrm{O}_{5}, 664.2996[\mathrm{M}+\mathrm{H}]^{+}$).

(R)-2-((1-(7-(But-2-yn-1-yl)-3-methyl-1-((4-methylquinazolin-2-yl)methyl)-2,6-dioxo-2,3,6,7-tetrahydro-1Hpurin-8-yl)piperidin-3-yl)carbamoyl)benzoic acid (3). To a stirred solution of compound $\mathbf{1 3}$ (5.0 g, $0.008 \mathrm{~mol})$ in $\mathrm{CH}_{2} \mathrm{Cl}_{2}(50.0 \mathrm{~mL})$ was added aqueous sodium hydroxide solution $(1.0 \mathrm{~g}$ of $\mathrm{NaOH}$ in $50.0 \mathrm{~mL}$ of $\left.\mathrm{H}_{2} \mathrm{O}\right)$ and tetra-n-butylammonium bromide $(0.27 \mathrm{~g}, 0.0008 \mathrm{~mol})$. Then maintained the reaction mass at $\mathrm{rt}$ for $72 \mathrm{~h}$. Then water phase was collected and washed with $\mathrm{CH}_{2} \mathrm{Cl}_{2}(25.0 \mathrm{~mL})$ for three times. To the stirred water phase was added $1 \mathrm{~mol} / \mathrm{L}$ aq. $\mathrm{HCl}(25.0 \mathrm{~mL})$ and maintained at $\mathrm{rt}$ for $30 \mathrm{~min}$. The isolated solid was collected by filtration and washed with water $(20.0 \mathrm{~mL})$ and $\mathrm{CH}_{2} \mathrm{Cl}_{2}(20.0 \mathrm{~mL})$. Then dried to yield 3 as a light yellow solid $(3.2 \mathrm{~g}, 62.2 \%)$, HPLC purity $97.34 \%$; m.p. $144-148{ }^{\circ} \mathrm{C} ;[\alpha]_{\mathrm{D}}^{20}-49.700\left(c=1 \mathrm{~g} / 100 \mathrm{~mL}\right.$, DMSO); IR (KBr) $v_{\max }: 3527$ (amide N-H $\left.{ }_{v}\right) ; 3255$ (acid O-H $\left.{ }_{v}\right) ; 3068\left(\right.$ aromatic C-H $\left.{ }_{v}\right) ; 2944,2856\left(\mathrm{C}-\mathrm{H}_{v}\right) ; 2224\left(\mathrm{C} \equiv \mathrm{C}_{v}\right) ; 1700,1654\left(\mathrm{C}=\mathrm{O}_{v}\right) ; 1573,1519$ 
(aromatic $\mathrm{C}=\mathrm{C}_{\nu}$, aromatic $\left.\mathrm{C}=\mathrm{N}_{\nu}\right) ; 1440,1400\left(\mathrm{C}-\mathrm{H}_{\delta}\right) ; 763\left(\operatorname{aromatic} \mathrm{C}-\mathrm{H}_{\gamma}\right) \mathrm{cm}^{-1} ;{ }^{1} \mathrm{H}-\mathrm{NMR}(400 \mathrm{MHz}$, DMSO- $\left.d_{6}\right) \delta 12.86(\mathrm{~s}, 1 \mathrm{H}), 8.35(\mathrm{~d}, J=7.8 \mathrm{~Hz}, 1 \mathrm{H}), 8.25(\mathrm{~d}, J=8.2 \mathrm{~Hz}, 1 \mathrm{H}), 7.96-7.89(\mathrm{~m}, 1 \mathrm{H}), 7.85-7.78$ $(\mathrm{m}, 2 \mathrm{H}), 7.68(\mathrm{t}, J=7.6 \mathrm{~Hz}, 1 \mathrm{H}), 7.59(\mathrm{td}, J=7.5,1.1 \mathrm{~Hz}, 1 \mathrm{H}), 7.51(\mathrm{td}, J=7.6,1.1 \mathrm{~Hz}, 1 \mathrm{H}), 7.41(\mathrm{~d}$, $J=7.4 \mathrm{~Hz}, 1 \mathrm{H}), 5.34(\mathrm{~s}, 2 \mathrm{H}), 4.92(\mathrm{q}, J=2.1 \mathrm{~Hz}, 2 \mathrm{H}), 4.10-4.01(\mathrm{~m}, 1 \mathrm{H}), 3.82(\mathrm{~m}, 1 \mathrm{H}), 3.63(\mathrm{~m}, 1 \mathrm{H}), 3.40(\mathrm{~s}$, not resolved, $\mathrm{CH}_{3}$ and water), 3.14-2.98 (m, 2H), $2.89(\mathrm{~s}, 3 \mathrm{H}), 2.02-1.86(\mathrm{~m}, 2 \mathrm{H}), 1.76$ (not resolved, 4H), $1.59(\mathrm{~m}, 1 \mathrm{H}) ;{ }^{13} \mathrm{C}-\mathrm{NMR}\left(100 \mathrm{MHz}, \mathrm{DMSO}-d_{6}\right) \delta 169.44,169.28,168.79,161.43,156.46,153.79,151.40$, $149.50,148.06,137.82,134.51,133.49,130.68,129.64,129.51,128.35,128.32,127.57,126.12,122.93,103.88$, 81.70, 74.26, 53.98, 50.43, 46.06, 46.01, 35.92, 29.91, 29.56, 23.56, 22.01, 3.56; HRMS (ESI) $m / z$ 621.2599 (calcd for $\mathrm{C}_{33} \mathrm{H}_{33} \mathrm{~N}_{8} \mathrm{O}_{5}, 621.2574[\mathrm{M}+\mathrm{H}]^{+}$).

N,N-bis((R)-1-(7-(But-2-yn-1-yl)-3-methyl-1-((4-methylquinazolin-2-yl)methyl)-2,6-dioxo-2,3,6,7-tetrahydro1H-purin-8-yl)piperidin-3-yl)phthalamide (4). Phthaloyl dichloride (1.0 g, $0.005 \mathrm{~mol})$ was added slowly to a stirred solution of $\mathbf{1}(4.8 \mathrm{~g}, 0.010 \mathrm{~mol})$ and triethylamine $(5.0 \mathrm{~g}, 0.05 \mathrm{~mol})$ in $\mathrm{CH}_{2} \mathrm{Cl}_{2}(50.0 \mathrm{~mL})$ at $\mathrm{rt}$ and refluxed for $24 \mathrm{~h}$. Then the mixture was cooled to rt and $1 \mathrm{~mol} / \mathrm{L}$ aq. $\mathrm{NaOH}(30 \mathrm{~mL})$ was added, and maintained for $2 \mathrm{~h}$. The isolated solid was collected by filtration and washed with water $(20.0 \mathrm{~mL})$, $\mathrm{CH}_{2} \mathrm{Cl}_{2}(20.0 \mathrm{~mL})$ and methanol $(20.0 \mathrm{~mL})$. Then dried to yield 4 as a light yellow solid $(3.5 \mathrm{~g}, 66.1 \%)$, HPLC purity 99.15\%; $[\alpha]_{\mathrm{D}}^{20}=-18.133\left(c=1 \mathrm{~g} / 100 \mathrm{~mL}, \mathrm{CHCl}_{3}\right)$; IR $(\mathrm{KBr}) v_{\max } 3243\left(\right.$ amide $\left.\mathrm{N}-\mathrm{H}_{v}\right)$; 3068 (aromatic $\left.\mathrm{C}-\mathrm{H}_{v}\right) ; 2945,2858\left(\mathrm{C}-\mathrm{H}_{v}\right) ; 2224\left(\mathrm{C} \equiv \mathrm{C}_{v}\right) ; 1700,1662\left(\mathrm{C}=\mathrm{O}_{v}\right) ; 1634,1563$, 1519 (aromatic $\mathrm{C}=\mathrm{C}_{v}$, aromatic $\left.\mathrm{C}=\mathrm{N}_{v}\right) ; 1440,1400\left(\mathrm{C}-\mathrm{H}_{\delta}\right) ; 763\left(\right.$ aromatic $\left.\mathrm{C}-\mathrm{H}_{\gamma}\right) \mathrm{cm}^{-1} ;{ }^{1} \mathrm{H}-\mathrm{NMR}\left(400 \mathrm{MHz}, \mathrm{DMSO}-d_{6}\right)$ $\delta 8.37(\mathrm{~d}, J=7.6 \mathrm{~Hz}, 1 \mathrm{H}), 8.22(\mathrm{~d}, J=8.1 \mathrm{~Hz}, 1 \mathrm{H}), 7.92-7.85(\mathrm{~m}, 1 \mathrm{H}), 7.79(\mathrm{~d}, J=8.3 \mathrm{~Hz}, 1 \mathrm{H}), 7.67-7.62$ $(\mathrm{m}, 1 \mathrm{H}), 7.50(\mathrm{~m}, 2 \mathrm{H}), 5.30(\mathrm{~s}, 2 \mathrm{H}), 4.90(\mathrm{~s}, 2 \mathrm{H}), 4.10-4.00(\mathrm{~m}, 1 \mathrm{H}), 3.81(\mathrm{~d}, J=9.0 \mathrm{~Hz}, 1 \mathrm{H}), 3.65(\mathrm{~m}, 1 \mathrm{H})$, $3.36(\mathrm{~s}, 3 \mathrm{H}), 3.15-2.99(\mathrm{~m}, 2 \mathrm{H}), 2.88(\mathrm{~s}, 3 \mathrm{H}), 1.98-1.84(\mathrm{~m}, 2 \mathrm{H}), 1.74$ (not resolved, 4H), 1.65-1.55 (m, $1 \mathrm{H}) ;{ }^{13} \mathrm{C}-\mathrm{NMR}\left(100 \mathrm{MHz}, \mathrm{CDCl}_{3}\right) \delta 168.68,168.52,161.01,155.73,154.36,151.71,149.89,147.29,135.04$, 133.23, 130.18, 128.80, 128.38, 126.71, 124.83, 123.10, 104.60, 81.53, 73.01, 53.57, 51.11, 46.32, 45.83, 35.63, 29.54, 28.76, 21.74, 21.67, 3.60; HRMS (ESI) $m / z 1075.4800\left(\right.$ calcd for $\mathrm{C}_{58} \mathrm{H}_{59} \mathrm{~N}_{16} \mathrm{O}_{6}, 1075.4803[\mathrm{M}+\mathrm{H}]^{+}$).

7-(But-2-yn-1-yl)-8-((2-hydroxyethyl)amino)-3-methyl-1-((4-methylquinazolin-2-yl)methyl)-1H-purine-2,6 $(3 \mathrm{H}, 7 \mathrm{H})$-dione (5). Ethanolamine $(8.0 \mathrm{~g}, 0.13 \mathrm{~mol})$ was added to a stirred solution of $\mathbf{1 1}(2.0 \mathrm{~g}, 0.0044 \mathrm{~mol})$ in toluene $(32.0 \mathrm{~mL})$ at reflux temperature and maintained for $2 \mathrm{~h}$. Then the mixture was cooled to rt and $20 \mathrm{~mL} \mathrm{H}_{2} \mathrm{O}$ was added, and stirred for $30 \mathrm{~min}$. The isolated solid was collected by filtration and washed with toluene $(10.0 \mathrm{~mL})$. Then dried to yield 5 as a white solid $(1.8 \mathrm{~g}, 94.2 \%)$, HPLC purity 99.61\%; m.p. 238-239 ${ }^{\circ} \mathrm{C}$; IR (KBr) $v_{\max } 3446,3364\left(\mathrm{~N}-\mathrm{H}_{v}, \mathrm{O}-\mathrm{H}_{v}\right) ; 2936,2867\left(\mathrm{C}-\mathrm{H}_{v}\right) ; 1702$, $1652\left(\mathrm{C}=\mathrm{O}_{v}\right) ; 1619,1581,1540\left(\right.$ aromatic $\mathrm{C}=\mathrm{C}_{v}$, aromatic $\left.\mathrm{C}=\mathrm{N}_{v}\right) ; 1448,1397\left(\mathrm{C}-\mathrm{H}_{\delta}\right) ; 1225\left(\mathrm{C}-\mathrm{O}_{v}\right) ; 764$ (aromatic C-H $\left.{ }_{\gamma}\right) \mathrm{cm}^{-1},{ }^{1} \mathrm{H}-\mathrm{NMR}\left(400 \mathrm{MHz}, \mathrm{DMSO}-d_{6}\right) \delta 8.25(\mathrm{~d}, J=8.0 \mathrm{~Hz}, 1 \mathrm{H}), 7.95-7.88(\mathrm{~m}, 1 \mathrm{H})$, $7.82(\mathrm{~d}, J=8.2 \mathrm{~Hz}, 1 \mathrm{H}), 7.72-7.62(\mathrm{~m}, 1 \mathrm{H}), 7.23(\mathrm{t}, J=5.6 \mathrm{~Hz}, 1 \mathrm{H}), 5.31(\mathrm{~s}, 2 \mathrm{H}), 4.89(\mathrm{q}, J=2.2 \mathrm{~Hz}, 2 \mathrm{H})$, $4.78(\mathrm{t}, J=5.5 \mathrm{~Hz}, 1 \mathrm{H}), 3.61(\mathrm{t}, J=6.0 \mathrm{~Hz}, 2 \mathrm{H}), 3.46(\mathrm{t}, J=6.0 \mathrm{~Hz}, 2 \mathrm{H}), 3.39(\mathrm{~s}, 3 \mathrm{H}), 2.89(\mathrm{~s}, 3 \mathrm{H}), 1.77(\mathrm{t}$, $J=2.1 \mathrm{~Hz}, 3 \mathrm{H}) ;{ }^{13} \mathrm{C}-\mathrm{NMR}\left(100 \mathrm{MHz}, \mathrm{DMSO}-d_{6}\right) \delta 169.19,161.68,154.38,152.99,151.50,149.54,149.52$, 134.45, 128.31, 127.51, 126.11, 122.92, 101.31, 81.06, 74.27, 60.20, 45.89, 45.56, 33.13, 29.80, 21.99, 3.57; HRMS (ESI) m/z 434.1937 (calcd for $\mathrm{C}_{22} \mathrm{H}_{24} \mathrm{~N}_{7} \mathrm{O}_{3}, 434.1941[\mathrm{M}+\mathrm{H}]^{+}$).

(R)-8-(3-Aminopiperidin-1-yl)-7-(but-2-yn-1-yl)-3-methyl-1H-purine-2,6(3H,7H)-dione(6). Diisopr opylethyl amine $(9.8 \mathrm{~g}, 0.076 \mathrm{~mol})$ was added to a stirred solution of $\mathbf{1 0}(5.0 \mathrm{~g}, 0.017 \mathrm{~mol})$ and $12(9.6 \mathrm{~g}, 0.025 \mathrm{~mol})$ in NMP $(50 \mathrm{~mL})$ and maintained the reaction mass at $100{ }^{\circ} \mathrm{C}$ for $13 \mathrm{~h}$. Then ethanolamine $(10.2 \mathrm{~g}$, $0.17 \mathrm{~mol}$ ) was added at $65^{\circ} \mathrm{C}$ and stirred for $4 \mathrm{~h}$ at $65^{\circ} \mathrm{C}$. The isolated solid was collected by filtration and washed with NMP (30 mL). Then dried to yield 6 as a off-white solid $(4.4 \mathrm{~g}, 82.7 \%)$, HPLC purity 99.36\%; m.p. 299-302 ${ }^{\circ} \mathrm{C}$; $[\alpha]_{\mathrm{D}}^{20}-3.467$ ( $\left.c=1 \mathrm{~g} / 100 \mathrm{~mL}, \mathrm{DMSO}\right) ; \mathrm{IR}(\mathrm{KBr}) v_{\max } 3115,3074$ (primary amine $\left.\mathrm{N}-\mathrm{H}_{v}\right) ; 3020\left(\right.$ imide $\left.\mathrm{N}-\mathrm{H}_{v}\right) ; 2947,2793\left(\mathrm{C}-\mathrm{H}_{v}\right) ; 2242\left(\mathrm{C} \equiv \mathrm{C}_{v}\right) ; 1706\left(\mathrm{C}=\mathrm{O}_{v}\right) ; 1660\left(\mathrm{C}=\mathrm{O}_{v}\right.$, primary amine $\left.\mathrm{N}-\mathrm{H}_{\delta}\right) ; 1610,1519\left(\mathrm{C}=\mathrm{C}_{v}, \mathrm{C}=\mathrm{N}_{v}\right) ; 1445,1384\left(\mathrm{C}-\mathrm{H}_{\delta}\right) \mathrm{cm}^{-1} ;{ }^{1} \mathrm{H}-\mathrm{NMR}\left(400 \mathrm{MHz}, \mathrm{DMSO}-d_{6}\right) \delta$ $10.94(\mathrm{~s}, 1 \mathrm{H}), 8.27(\mathrm{~s}, 2 \mathrm{H}), 4.92(\mathrm{q}, J=2.4 \mathrm{~Hz}, 2 \mathrm{H}), 3.65(\mathrm{~m}, 1 \mathrm{H}), 3.48-3.40(\mathrm{~m}, 1 \mathrm{H}), 3.33$ (incompletely resolved, $4 \mathrm{H}), 3.15(\mathrm{~m}, 2 \mathrm{H}), 2.00(\mathrm{~m}, 1 \mathrm{H}), 1.96-1.85(\mathrm{~m}, 1 \mathrm{H}), 1.81(\mathrm{t}, J=2.2 \mathrm{~Hz}, 3 \mathrm{H}), 1.67(\mathrm{~m}, 2 \mathrm{H})$; 
${ }^{13} \mathrm{C}-\mathrm{NMR}\left(100 \mathrm{MHz}, \mathrm{DMSO}-d_{6}\right) \delta 154.97,153.99,150.76,148.37,103.93,81.20,73.75,51.43,50.33,46.09$, 35.16, 28.49, 27.27, 21.85, 3.14; HRMS (ESI) $m / z 317.1714$ (calcd for $\mathrm{C}_{15} \mathrm{H}_{20} \mathrm{~N}_{6} \mathrm{O}_{2}, 317.1721[\mathrm{M}+\mathrm{H}]^{+}$).

\section{Conclusions}

Five new process-related impurities detected by HPLC varying from $0.15 \%$ to $0.5 \%$ were identified, synthesized, and subsequently characterized by HPLC, MS, HRMS, ${ }^{1} \mathrm{H}-\mathrm{NMR},{ }^{13} \mathrm{C}-\mathrm{NMR}$ (DEPT) and IR techniques.

We have developed appropriate in-process checks and strategies in order to control these impurities within the acceptable level. For example, impurities 3,4 and 5 could be reduced to below the identification threshold of $0.1 \%$ by salifying linagliptin with hydrochloric acid while impurities 2 and 6 could be controlled within $0.1 \%$ by recrystallization from toluene. The detection limit of impurities 2, 3, 4 and 5 was $0.10 \mu \mathrm{g} / \mathrm{mL}$ or $0.02 \%$ while the detection limit of impurity 6 was $0.15 \mu \mathrm{g} / \mathrm{mL}$ or $0.03 \%$. Our efforts to synthesize and characterize them effectively prove to be valuable when it comes to complying with the regulatory norms as well as assessing the quality of linagliptin.

Supplementary Materials: Supplementary materials can be accessed at: http://www.mdpi.com/1420-3049/21/ 8/1041/s1.

Acknowledgments: The authors are thankful to the teachers of the China State Institute of Pharmaceutical Industry for supporting this study and the cooperation from other colleagues is also highly appreciated.

Author Contributions: Yiwen Huang designed and carried out the synthetic experiments, analyzed the data and wrote the paper. Xiaoqing He performed HPLC analysis and other analysis work. Taizhi Wu and Fuli Zhang reviewed and edited the manuscript. All authors read and approved the manuscript.

Conflicts of Interest: The authors declare no conflict of interest.

\section{References}

1. Szekely, G.; Amores de Sousa, M.C.; Gil, M.; Castelo Ferreira, F.; Heggie, W. Genotoxic impurities in pharmaceutical manufacturing: Sources, regulations, and mitigation. Chem. Rev. 2015, 115, 8182-8229. [CrossRef] [PubMed]

2. ICH Harmonised Tripartite Guideline: Impurities in new drug substances Q3A(R2). In Proceedings of the International Conference on Harmonization of Technical Requirements for Registration of Pharmaceuticals for Human Use, Geneva, Switzerland, 25 October 2006.

3. Thomas, L.; Eckhardt, M.; Langkopf, E.; Tadayyon, M.; Himmelsbach, F.; Mark, M. (R)-8-(3-aminopiperidin-1-yl)-7-but-2-ynyl-3-methyl-1-(4-methyl-quinazolin-2-ylmethyl)-3,7-dihydro-purine-2,6-dione (BI 1356), a novel xanthine-based dipeptidyl peptidase 4 inhibitor, has a superior potency and longer duration of action compared with other dipeptidyl peptidase-4 inhibitors. J. Pharmacol. Exp. Ther. 2008, 325, 175-182. [PubMed]

4. Pfrengle, W.; Pachur, T.; Nicola, T.; Duran, A. Method for Producing Chiral 8-(3-Amino-piperidin-1-yl)Xanthines. WO 2006048427, 2 August 2006.

5. Nandi, S.; Reddy, A.N.G.; Reddy, P.V.A.S.P.; Reddy, K.S.K. Process related impurities in anti-diabetic drug linagliptin. J. Pharm. Res. Opin. 2015, 5. [CrossRef]

6. Parsha, S.; Kumar, Y.R.; Ravichander, M. LC-MS/MS and NMR characterization of key impurities in linagliptin and pramipexole. J. Liq. Chromatogr. Relat. Technol. 2015, 38, 1699-1712. [CrossRef]

7. Mascia, S.; Heider, P.L.; Zhang, H.; Lakerveld, R.; Benyahia, B.; Barton, P.I.; Braatz, R.D.; Cooney, C.L.; Evans, J.M.B.; Jamison, T.F.; et al. End-to-end continuous manufacturing of pharmaceuticals: Integrated synthesis, purification, and final dosage formation. Angew. Chem. Int. Ed. 2013, 52, 12359-12363. [CrossRef] [PubMed]

8. Szekely, G.; Gil, M.; Sellergren, B.; Heggie, W.; Ferreira, F.C. Environmental and economic analysis for selection and engineering sustainable api degenotoxification processes. Green Chem. 2013, 15, 210-225. [CrossRef]

9. Székely, G.; Valtcheva, I.B.; Kim, J.F.; Livingston, A.G. Molecularly imprinted organic solvent nanofiltration membranes-Revealing molecular recognition and solute rejection behaviour. React. Funct. Polym. 2015, 86, 215-224. [CrossRef] 
10. Sumner, N. Developing counter current chromatography to meet the needs of pharmaceutical discovery. J. Chromatogr. A 2011, 1218, 6107-6113. [CrossRef] [PubMed]

Sample Availability: Samples of the compounds 1-6 are available from the authors. article distributed under the terms and conditions of the Creative Commons Attribution (CC-BY) license (http://creativecommons.org/licenses/by/4.0/). 